\title{
Method of Changing the Structure of Cast Fe-Al Alloys By Inputting Titanium-containing Modifiers
}

\author{
S.Yu. Melchakov¹, V.G. Smirnova ${ }^{1}$, V.P. Ermakova1, V.V. Kataev ${ }^{1}$,L.A. Marshuk1, \\ I.V. Nekrasov', and O.Yu. Sheshukov ${ }^{1,2}$ \\ ${ }^{1}$ Institute of Metallurgy of Ural Branch of Russian Academy of Sciences, 101, Amundsen Street, \\ Ekaterinburg, Russia, 620016 \\ ${ }^{2}$ Ural Federal University named after the first President of Russia B.N. Yeltsin, 19, Mira Street, \\ Ekaterinburg, Russia, 620016
}

\section{Abstract}

Iron-aluminum alloys with a high (more than $10 \mathrm{wt} . \%$ ) aluminum content are alloys with sufficiently high heat resistance and can be considered as an alternative to expensive superalloys containing nickel and chromium. A method is proposed for obtaining an equiaxial structure in cast alloys of Fe- (12-14 wt.\%) Al. Alloys were smelted in an open

Corresponding Author:

S.Yu. Melchakov

s.yu.melchakov@gmail.com

Received: 5 February 2019

Accepted: 6 March 2019

Published: 17 March 2019

Publishing services provided by

Knowledge E

(c) S.Yu. Melchakov et al. This article is distributed under the terms of the Creative Commons

Attribution License, which

permits unrestricted use and

redistribution provided that the

original author and source are credited.

Selection and Peer-review under the responsibility of the NIOKR-2018 Conference Committee. mid-frequency induction furnace by introducing titanium-containing modifiers, which can act as crystallization centers during melt solidification when they are introduced into a liquid metal, helping to obtain an optimal grain structure of the solid metal. Several modifications were used: FeTi30, FeTi30 with the addition of metallic zirconium and the complex microcrystalline modifier "Insteel 7". All modifiers contained varying amounts of titanium. They were introduced into the melt of Fe-Al alloys 5 minutes before the metal was drained. The purpose of this study was to obtain an equiaxed grain structure of the alloys in the solid state. The desired grain shapes were achieved by introducing the FeTi30 modifier when the total titanium content in the ingot was more than $1.2 \%$ by weight. Another way to obtain the optimal structure was the introduction of FeTi3O with the addition of metallic zirconium (1.83 wt.\% $\mathrm{Ti}$ and $0.3 \% \mathrm{Zr}$ in the ingot). The use of the Insteel 7 modifier, consisting of $\mathrm{Ca}, \mathrm{Ba}, \mathrm{Fe}, \mathrm{Ti}, \mathrm{Ce}$, and La in the form of complex silicides, is impractical because its use does not allow obtaining an equiaxial or close to equiaxial granular structure of cast Fe-Al alloys.

Keywords: cast Fe-Al alloys, an open mid-frequency induction furnace, FeTi30 modifier, zirconium, Insteel 7 complex modifier, grain structure, rare earth metals silicide

\section{Introduction}

Most of the elements introduced into the steel for alloying, deoxidizing or modifying are used in the form of ferroalloys. According to [1], modifiers also belong to ferroalloys, differing from them only by their purpose. Modifiers [2-4] are substances whose small 
amounts significantly alter the structure and, therefore, the properties of the metal or alloy they have processed. Studied in this work titanium containing modifiers are belong to modifiers of the second kind (or so-called inoculators), according to the classification of P.A. Rebinder [5]. Such modifiers, when introduced into the melt, either inhibit the growth of nuclei or are themselves additional crystallization centers, forming refractory compounds with steel components. These compounds play the role of crystallization centers during solidification of the melt, helping to obtain a fine-grained solid metal structure.

It is known [6,7], that titanium is widely used in metallurgy as a deoxidizing agent, alloying element and as a modifying additive. In this work, the task was to analyze the effect of modification (inoculation) with titanium in the form of "FeTi30" ferroalloy or in the form of a microcrystalline complex modifier "Insteel 7" on the grain structure of casted Fe-Al alloys with high (12 and 14 wt.\%) aluminum content. According to the authors of [8], joint modification with two or more modifiers is often more effective than with one. Therefore, we made a joint modification with two modifiers: ferrotitanium (FeTi30) and zirconium to enhance the grinding effect on the structure [9].

\section{Samples and Experimental Technique}

The studied Fe-Al alloys were obtained in an open mid-frequency induction furnace with a capacity of $500 \mathrm{~g}$ and a power of $15 \mathrm{~kW}$. Smelting of iron and aluminum consisted of several spills at a temperature of $1580^{\circ} \mathrm{C}$. Then liquid metal poured out into a heated $\left(200^{\circ} \mathrm{C}\right)$ graphite mold. Various modifiers (the composition of the modifiers (wt.\%) was determined by chemical analysis) were introduced into the Fe-Al melt in an aluminum foil capsule in 5 minutes before the metal was drained. One melting \#1 was without a modifier. Following amounts of modifiers were added: Melting \#II $-33.23 \mathrm{~kg} / \mathrm{t}$ of FeTi30 (30.1\% Ti; 11.8\% Al; 5.24\% Si; 1.06\% Mn; 0.147\% C; 0.05\% P; 0.0035\% S; 0.12\% Cu; 0.1\% V; 0.007\% Mo; 0.004\% Zr; 0.005\% Sn; rest Fe); Melting \#III - 67.65 kg/t of FeTi30; Melting \#IV - $31.95 \mathrm{~kg} / \mathrm{t}$ of FeTi30 and $0.96 \mathrm{~kg} / \mathrm{t}$ of zirconium $(99.85 \% \mathrm{Zr} ; 0.0025 \% \mathrm{Cr} ; 0.016 \%$ Si; $0.0011 \% \mathrm{Ni} ; 0.122 \% \mathrm{Fe}$; 0.0019\% O; 0.001\% N); Melting \#V - $62.06 \mathrm{~kg} / \mathrm{t}$ of FeTi30 and $1.88 \mathrm{~kg} / \mathrm{t}$ of zirconium; Melting \#VI - $76.78 \mathrm{~kg} / \mathrm{t}$ of Insteel 7 (16.7\% Ti; 49.9\% Si; 8.2\% Ba; 7.9\% Ca; 2.65\% La; 3.61\% Ce; 0.62\% N; 0, 28\% O; 0.43\% C; 1.02\% Al; 0.63\% Mg; rest Fe); Melting \#VII $-80.27 \mathrm{~kg} / \mathrm{t}$ of Insteel 7. The surface of the melt was protected by preparing slag consisting of (wt.\%) 23\% $\mathrm{CaO}, 11 \% \mathrm{MgO}, 50 \% \mathrm{SiO}_{2}$ and $16 \% \mathrm{Al}_{2} \mathrm{O}_{3}$. For stress relief, ingots with a diameter of $14.3 \mathrm{~mm}$ and a height of $131 \mathrm{~mm}$ were placed in a chamber of electrical resistance furnace with an air atmosphere, kept for one hour at $1000{ }^{\circ} \mathrm{C}$ 
and cooled with a furnace. After this treatment, samples with a diameter of $5 \mathrm{~mm}$ and a height of $10 \mathrm{~mm}$ were cut from the central part of the ingots at a height of $60 \mathrm{~mm}$ from the bottom for the manufacture of microsections. The metallographic study was performed on an NEOPHOT-2 microscope and a Micromet-5103 micro-hardness meter equipped with a Thixomet Pro image analyzer, which allows obtaining panoramic images of the microstructure of steel.

To determine the phase composition of the alloys, a Carl Zeiss EVO 40 scanning electron microscope with INCA X-Act Oxford Instruments SDD spectrometer for Energy Dispersive Spectroscopy (EDS) was used. Chemical analysis of modifiers and alloys was carried out using atomic emission spectrometers with inductively coupled plasma SpectroFlame Modula S and Optima 2100 DV. The carbon content was determined on a Leco CS-230 instrument. The content of nitrogen and oxygen was determined on an ELTRA ONH-2000 analyzer. On the panoramic images of the structure of the alloys with an area of around $20 \mathrm{~mm}^{2}$, we estimated (according to [10]) the morphology and size of the primary grains before and after modification. The shape factor $\left(\mathrm{K}_{f}\right)$ of grains we calculated as the ratio of the length of grain along the heat removal line during metal crystallization to the grain size in the transverse direction.

\section{Results and Discussion}

Table 1 shows the chemical composition of the alloys under study before and after treatment with various modifiers.

With the help of EDS-analysis, the phase composition of FeTi30 modifier introduced into the Fe-Al alloys was analyzed. It is found that the matrix is a solid solution of titanium (30\%), silicon (4.5\%) and aluminum (10\%) in iron. The authors of [6] give similar data on the composition of the matrix of aluminothermic ferrotitanium but believe that the solid solution is similar in composition to the compound of $\mathrm{Fe}_{2} \mathrm{Ti}$. Besides, inclusions of corundum $\mathrm{Al}_{2} \mathrm{O}_{3}$ in the form of particles of geometric shape and large (up to $100 \mu \mathrm{m}$ in length) dendrite-like titanium carbide precipitates were found in the matrix. Exactly particles of $\mathrm{TiC}$, the melting point of which exceeds $2500^{\circ} \mathrm{C}$, can act as inoculators necessary for obtaining a fine-grained structure in the studied alloys. A general view of FeTi30 microstructure is shown in Figure 1.

The phase composition of the Insteel 7 complex modifier is much more complicated. There are six phases found in it: $\mathrm{TiFeSi}_{2} ; \mathrm{CaSi}_{2} ; \mathrm{Ca}_{1-x}(\mathrm{La}, \mathrm{Ce}) \mathrm{Si}_{2} ; \mathrm{FeSi}_{2}$; complex phase based on $\mathrm{BaSi}_{2}$, containing $\mathrm{Ca}, \mathrm{Si}, \mathrm{Al}$ and $\mathrm{Mg}$, and $\mathrm{TiCN}$. Titanium presented in the most numerous phase of $\mathrm{TiFeSi}_{2}$ and in the composition of a small number of inclusions of 


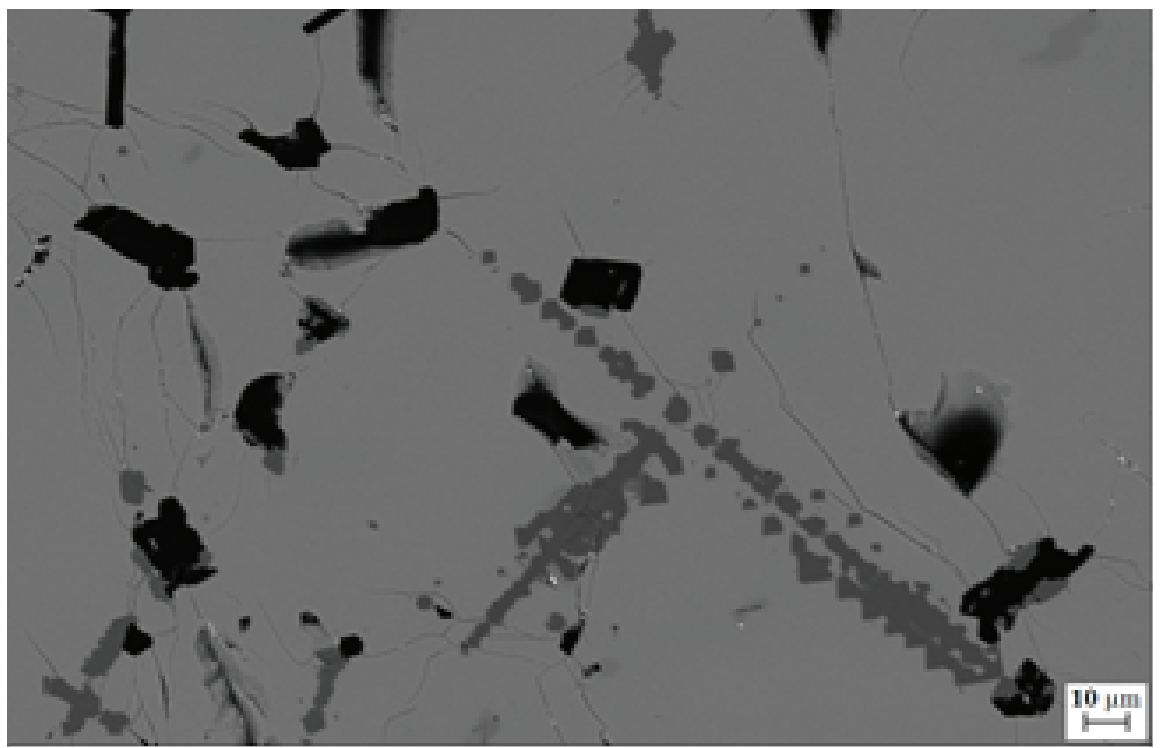

Figure 1: SEM image of FeTi30 microstructure: 1 - matrix (solid solution of titanium (30\%); silicon (4.5\%) and aluminum (10\%) in iron); 2 - corundum $\left(\mathrm{Al}_{2} \mathrm{O}_{3}\right.$ ) (black inclusions); 3 - titanium carbide (TiC) (dark grey dendrites).

TABLE 1: Composition (wt. \%) of alloys before and after modification.

\begin{tabular}{l|l|c|c|c|c|c|c|c|c|c|} 
Melting & Modifier & $\mathbf{C}$ & $\mathbf{M n}$ & $\mathbf{A l}$ & $\mathbf{T i}$ & $\mathbf{Z r}$ & $\mathbf{S i}$ & $\mathbf{C e}$ & $\mathbf{L a}$ & $\mathbf{B a}$ \\
\hline \#I & Not introduced & 0.008 & 0.17 & 11.8 & - & - & 0.22 & - & - & - \\
\hline \#II & FeTi30 & 0.048 & 0.13 & 11.9 & 1.03 & - & 0.65 & - & - & - \\
\hline \#III & FeTi30 & 0.007 & 0.16 & 13.7 & 1.20 & - & 0.62 & - & - & - \\
\hline \#IV & FeTi30 + Zr & 0.007 & 0.12 & 12.9 & 1.13 & 0.13 & 0.40 & - & - & - \\
\#V & FeTi30 + Zr & 0.008 & 0.12 & 12.1 & 1.83 & 0.30 & 0.41 & - & - & - \\
\hline \#VI & Insteel 7 & 0.024 & 0.17 & 12.7 & 1.02 & - & 2.49 & 0.037 & 0.017 & 0.005 \\
\#VII & Insteel 7 & 0.034 & 0.19 & 14.2 & 1.27 & - & 2.93 & 0.033 & 0.013 & 0.005
\end{tabular}

titanium carbonitride. Rare earth metals in modifier Insteel 7 are found only as part of complex silicide $\mathrm{Ca}_{1-x}(\mathrm{La}, \mathrm{Ce})_{x} \mathrm{Si}_{2}$. Figure 2 shows the structure of the modifier.

The panoramas of the grain structure of the alloys under study before and after the modification are shown in Figure 3.

In Figure 3(a), it can be seen that the alloy before the modification (melting \#I) has a characteristic column structure. The grains grow to the center of the ingot in the direction opposite to the heat removal, and have fairly smooth boundaries. In the structure of ingot \#II (1.03\% Ti), in which the FeTi30 modifier was introduced, two zones were found: a zone of columnar crystals, which occupies about $75 \%$ of the surface, and a zone of equiaxial or close to equiaxial crystals, occupying approximately $25 \%$ of the sample surface (Table 2). The columnar grains themselves are very narrow and long, and their borders have an uneven, tortuous and often stepped shape - Figure 3(b). In the structure of melting \#III (1.20\% Ti), after modifying with FeTi30, the zone of columnar crystals is completely 


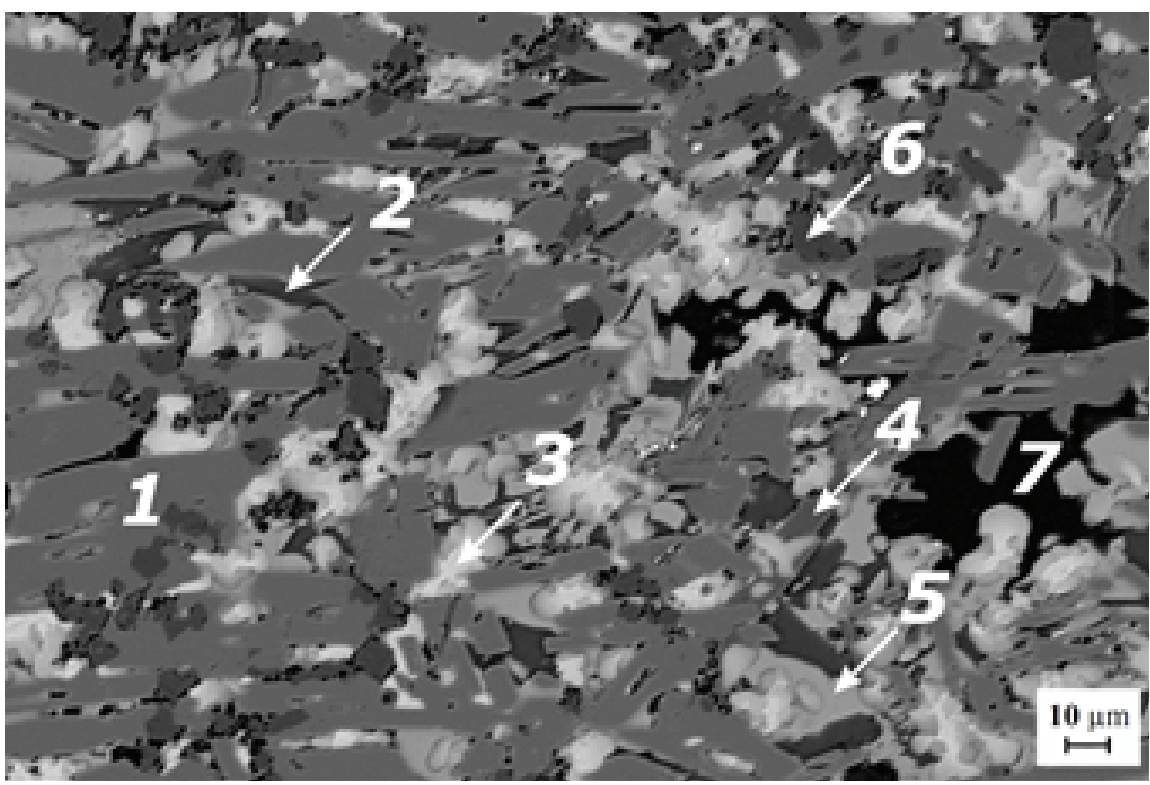

Figure 2: SEM image of Insteel 7 modifier microstructure: $1-\mathrm{TiFeSi}_{2} ; 2-\mathrm{CaSi}_{2} ; 3-\mathrm{Ca}_{1-x}(\mathrm{La}, \mathrm{Ce})_{x} \mathrm{Si}_{2} ; 4-$ $\mathrm{FeSi}_{2} ; 5$ - phase based on $\mathrm{BaSi}_{2}$, containing $\mathrm{Ca}$, Si; Al and Mg; 6-TiCN; 7-pore.

absent, and the entire area of the sample is occupied by a zone of grains that are close to equiaxial - Figure 3(c).

After modifying with two components: FeTi30 + zirconium (meltings \#IV, \#V), the alloys have a structure that is rather close to equiaxial - Figures 3(d) and 3(e). Moreover, in melting \# $\mathrm{V}$ (Figure 3(f)), in which more titanium and zirconium were introduced (see Table 1), the grain shape is closer to the equiaxial. The value of $\mathrm{K}_{f}$, which characterizes, first of all, the shape of the grain, in the metal structure of melting \# $\mathrm{V}$ is noticeably lower than in meltings \#II, \#III, and \#IV (as shown in Table 2).

TABLE 2: Parameters of the grain structure of Fe-Al alloys.

\begin{tabular}{|c|c|c|c|c|c|c|}
\hline \multirow[t]{2}{*}{ Melting } & \multirow[t]{2}{*}{ Type of modifier } & \multirow{2}{*}{$\begin{array}{c}\text { Content of } \mathrm{Ti} \\
\text { in the alloys, } \\
\text { wt. } \%\end{array}$} & \multicolumn{2}{|c|}{$\begin{array}{l}\text { The extent of the zone } \\
\text { vol. \% }\end{array}$} & \multicolumn{2}{|c|}{ Shape coefficient* $\left(K_{f}\right)$} \\
\hline & & & $\begin{array}{l}\text { Column } \\
\text { grains }\end{array}$ & $\begin{array}{l}\text { Equiaxial } \\
\text { grains }\end{array}$ & $\begin{array}{l}\text { Column } \\
\text { grains }\end{array}$ & $\begin{array}{l}\text { Equiaxial } \\
\text { grains }\end{array}$ \\
\hline$\# 1$ & Not introduced & 0 & 100 & 0 & 4.2 & No \\
\hline \#II & FeTi30 & 1.03 & 75 & 25 & 2.5 & 1.4 \\
\hline \#III & FeTi30 & 1.20 & 0 & 100 & No & 1.5 \\
\hline \#IV & $\mathrm{FeTi} 30+\mathrm{Zr}$ & 1.13 & 0 & 100 & No & 1.8 \\
\hline$\# \mathrm{~V}$ & $\mathrm{FeTi30+Zr}$ & 1.83 & 0 & 100 & No & 1.3 \\
\hline$\# \mathrm{VI}$ & Insteel 7 & 1.02 & 56 & 44 & 4.3 & 1.6 \\
\hline \#УII & Insteel 7 & 1.27 & 35 & 65 & 4.9 & 1.2 \\
\hline
\end{tabular}



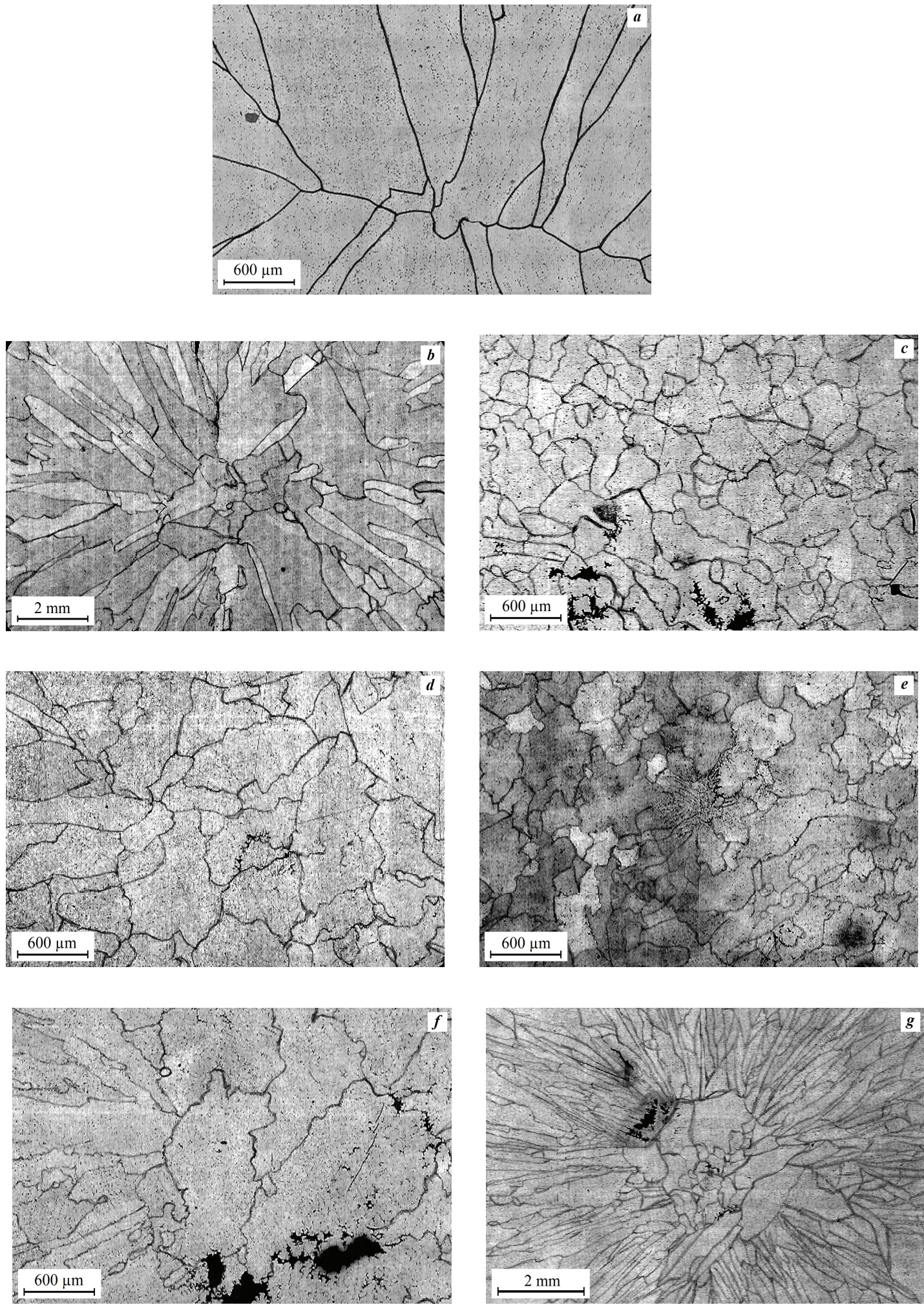

Figure 3: The grain structure of cast Fe-Al alloys: $a$ - before modification; $b$ - after inputting of FeTi30 (1.03\% Ti); c - after inputting of FeTi30 (1.20\% Ti); d - after inputting of FeTi30 (1.13\% Ti) and Zr (0.13\%); e - after inputting of $\mathrm{FeTi} 30$ (1.83\% Ti) and $\mathrm{Zr}(0.30 \%) ; \mathrm{f}-$ after inputting of Insteel 7 (1.02\% Ti); $\mathrm{g}$ - after inputting of Insteel 7 (1.27\% Ti). 
The fact that the structure of alloys modified with titanium and zirconium (melting \#IV and \# $\#$ ) is much closer to equiaxial than in a metal modified only with titanium (melting \#II and \#III) can be explained using EDS-analysis. This method allows us to conclude, that in the microstructure of ingots \#IV and \#V are present particles of mixed carbides of titanium and zirconium, which are good inoculators - Figure 4. Moreover, in melting \# $\mathrm{V}$ that contains more carbon, titanium, and zirconium (see Table 1) the effect of modifying is higher than in \#IV. Besides, in the metal matrix of ingots \#IV and \#V, the spherical inclusions consisting of silicon, zirconium, iron, carbon, and aluminum were found. And also at the grain frontiers, there were films (Figure 5) containing titanium, zirconium, silicon, and carbon. Exactly these films play the role of modifiers or inoculators of the second kind [5] since they are mainly located at the grain boundaries. Films restrain the growth of grains during solidification of the liquid metal.

After modifying alloys with the Insteel 7 complex modifier (melting \#VI and \#VII), the structure of the alloys has two zones - a zone with columnar grains and a zone in which equiaxed or close to equiaxial grains prevail - see Figures $3(f)$ and $3(\mathrm{~g})$. In melting \#VII, where titanium content in the metal is more than $1.27 \mathrm{wt} . \%$, the columnar zone occupies about 35\% of the sample area, whereas in melting \#VI (with the titanium content of 1.02 wt.\%) it occupies approximately $56 \%$ (see Table 2). The zone of grains with shapes close to equiaxed in the alloy with a higher titanium content (melting \#VII) occupies about 65\% of the sample area (Figures 3(f) and 3(g), Table 2) that is bigger than in alloy \#VI.

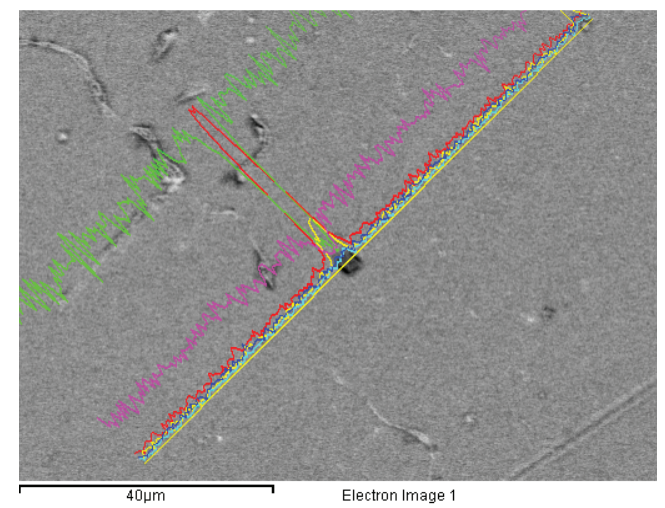

$a$

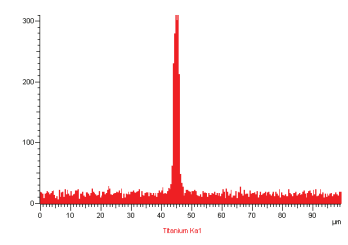

$\boldsymbol{b}$

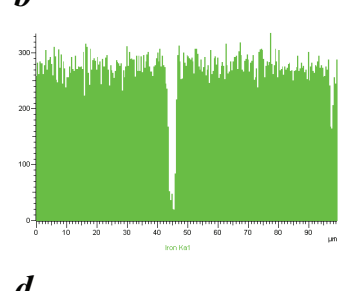

$d$

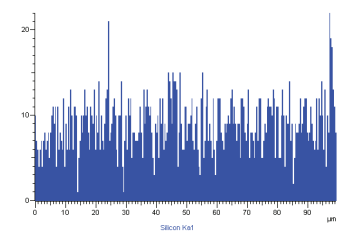

$f$

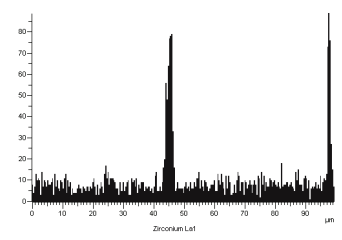

c
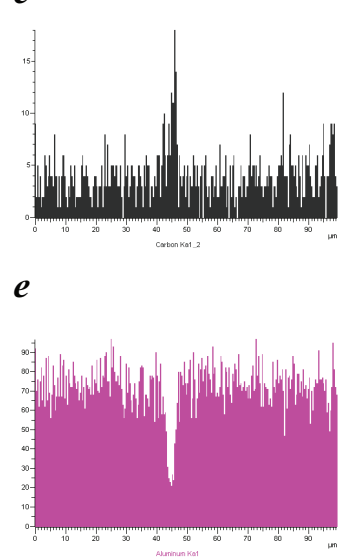

$g$

Figure 4: SEM image of the microstructure and non-metal phase in the alloy \# $\mathrm{V}(\mathrm{a})$ and the distribution of elements along the scanning line: $\operatorname{Ti}(\mathrm{b}), \mathrm{Zr}(\mathrm{c}), \mathrm{Fe}(\mathrm{d}), \mathrm{C}(\mathrm{e}), \mathrm{Si}(\mathrm{f}), \mathrm{Al}(\mathrm{g})$. 




$a$

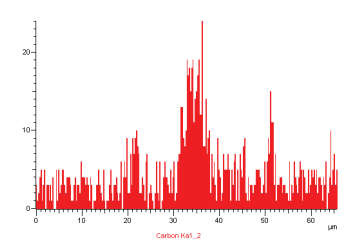

b
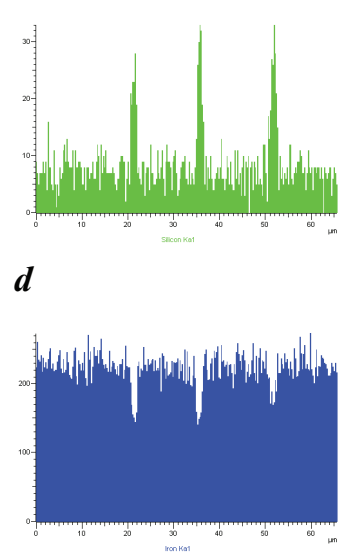

$f$

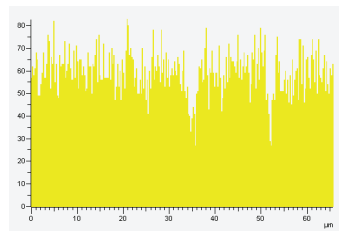

$c$

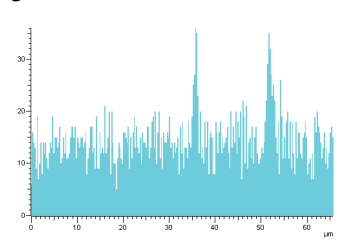

$\boldsymbol{e}$

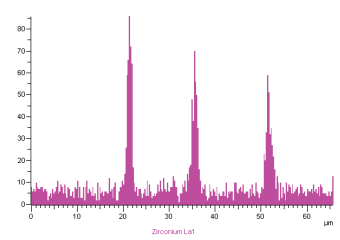

$g$

Figure 5: SEM image of the microstructure and films in the alloy \# $\mathrm{V}$ (a) and the distribution of elements along the scanning line: $\mathrm{C}$ (b), $\mathrm{Al}(\mathrm{c}), \mathrm{Si}(\mathrm{d}), \mathrm{Ti}(\mathrm{e}), \mathrm{Fe}(\mathrm{f}), \mathrm{Zr}(\mathrm{g})$.

We should not have expected, in our opinion, that the rare earth metals in the Insteel 7 will have a noticeable positive effect on the grain structure of the modified alloys. Lanthanum and cerium within the Insteel 7 modifier are bound in chemically inactive silicide [11]. For the same reason titanium does not have a positive effect on the structure of the modified alloy, although its content in melting $\# \mathrm{VII}$ is rather high $-1.2 \%$, since it is also present in the composition of silicides $-\mathrm{TiFeSi}_{2}$. In addition, the probability of improving the grain structure using titanium carbonitride particles, playing the role of inoculators, is not very high, because their amount in Insteel 7 is slight.

According to the chemical analysis data, the FeTi30 modifier contains $0.23 \% \mathrm{O}$ and $0.0079 \%$ N. In composition of FeTi30 modifier (see Figure 1) corundum particles and coarse titanium carbide precipitates are present. In alloys \#II and \#III, modified only with FeTi30, titanium carbides were not detected, probably, due to their very small size, but particles of titanium and zirconium carbonitrides were found in ingots \#4 and \#5. These inclusions, which act as [5] inoculators, appeared, in our opinion, due to the increased content of carbon and nitrogen in the FeTi30 modifier, and contributed to the appearance of a zone of equiaxial crystals during solidification of the metal melt after the introduction of this modifier. The total nitrogen content in all alloys increases by about $50-80 \%$ during the modification as shown in Table 3.

The inclusions of corundum contained in the FeTi30 modifier and formed in the treated metal due to the oxidation of aluminum did not affect the grain structure of the 
alloy. Corundum did not act as inoculator since it has good buoyancy in slag [12]. For the same reason, apparently, the oxygen content in the alloys did not increase after the modification, but contrary, decreased by 30-45 wt. \% (See Table 3).

TABLE 3: Content (wt.\%) of gases in Fe-Al alloys.

$\begin{array}{ll}\text { Melting } & \text { Modifier } \\ \text { \#I } & \text { No } \\ \text { \#II } & \text { FeTi30 (1.03\%Ti) } \\ \text { \#III } & \text { FeTi30 (1.20\%Ti) } \\ \text { \#IV } & \text { FeTi30 (1.13\%Ti) + Zr } \\ & (0.13 \%) \\ \text { \#V } & \text { FeTi30 (1.83\%Ti) + Zr } \\ & \text { (0.30\%) } \\ \text { \#VI } & \text { Insteel 7 } \\ \text { \#VII } & \text { Insteel 7 }\end{array}$

\begin{tabular}{|c|}
\hline 0 \\
\hline 0.0055 \\
\hline 0.0034 \\
\hline 0.0030 \\
\hline 0.0038 \\
\hline 0.0039 \\
\hline 0.0085 \\
\hline 0.0016 \\
\hline
\end{tabular}

\begin{tabular}{|c|}
\hline $\mathbf{N}$ \\
\hline 0.0019 \\
\hline 0.0024 \\
\hline 0.0090 \\
\hline 0.0023 \\
\hline 0.0039 \\
\hline 0.0044 \\
\hline 0.0038 \\
\hline
\end{tabular}

\section{Conclusion}

Thus, it is possible to affect the structure of Fe-(12-14\%)Al alloys and to obtain a structure close to equiaxial by introducing FeTi30 ferroalloy. But it works only when at least 1.2 wt.\% of Ti contains in the metal ingot. Another way to obtain an equiaxed structure of grains is possible by the joint inputting of FeTi30(1.83 wt.\%) and zirconium (0.30 wt.\%). The authors of this work consider no expedient to use the Insteel 7 complex modifier containing $16.7 \% \mathrm{Ti}$ to improve the structure of Fe-(12-14\%) Al alloys. Since inputting of this modifier does not allow to get an equiaxial (or close to equiaxial) grain structure of the metal.

The work was performed as part of the State topic "Structural, physicochemical and mechanical properties of aluminum and copper alloys and composites for structural and electrical purposes" (No. 0396-2015-0078) using the equipment of the "Ural-M" Collective Use Center

\section{References}

[1] Gasik, M.I. and Lyakishev, N.P. (1999). Theory and technology of electrometallurgy of ferroalloys. Textbook for universities. Moscow: Sp Intermet Inzhiniring (in Russian).

[2] Shub, L.B. and Akhmadeyev, A.Yu. (2006). About the advisability of modifying steel casting. Metallurgiya mashinostroyeniya, no.5, pp. 38-41 (in Russian). 
[3] Goldstein, Ya.E. and Mizin, V.G. (1986). Modifying and micro-alloying of cast iron and steel. Moscow: Metallurgiya (in Russian).

[4] Maltsev, M.V. (1964). Modification of the structure of metals and alloys. Moscow: Metallurgiya (in Russian).

[5] Rebinder, P.A. (1978). Selected Works. Surface phenomena in dispersed systems. Colloid chemistry. Moscow: Nauka (in Russian).

[6] Gasik, L.N., Ignatov, V.S. and Gasik, M.I. (1975) Structure and quality of industrial ferroalloys and master alloys. Kiev: Tekhnika (in Russian).

[7] Garmata, V.A., Petrunko, A.N., Galitskiy N.V. et al. (1983). Titanium. Moscow: Metallurgiya (in Russian).

[8] Goldstein, Ya.E. (1960). Micro-alloying of steel and cast iron. Moscow-Sverdlovsk: Mashgiz (in Russian).

[9] Berlin, E.N., and Karasev, A.I. Boron, calcium, niobium and zirconium in cast iron and steel. (1961). Moscow: Metallurgizdat (in Russian).

[10] Saltykov, S.A. (1970). Stereometric metallography. Moscow: Metallurgiya (in Russian).

[11] Waudby, P.E. (1978). Rare earth additions to steel. International Metals Reviews, no. 2, pp. 74-98.

[12] Povolotskiy, D.Ya., Roshchin, V.Ye., Ryss, M.A., et al. (1974). Electrometallurgy of steel and ferroalloys. Moscow: Metallurgiya (in Russian). 